${ }^{1}$ Dept. of Occupational and Environmental Medicine, Odense University Hospital, DK-5000 Odense C, Denmark.

${ }^{2}$ Institute and Outpatient Clinic for Occupational, Social and Environmental Medicine, WHO Collaborating Centre for Occupational Health, University Hospital Munich, LMU Munich, Germany

${ }^{3}$ Institute of Environmental Medicine, Karolinska Institutet, Stockholm, Sweden

${ }^{4}$ Department of Occupational and Environmental Medicine, Bispebjerg University Hospital, Copenhagen, Denmark

${ }^{5}$ National Institutes of Health, University of the Philippines Manila (UPM), Manila Philippines

${ }^{6}$ College of Arts and Sciences, University of the Philippines Manila, Philippines

\section{7a SHORT INTRODUCTION TO THE MINIMATA RESOLUTION AND HEALTH CONSEQUENCES OF MERCURY VERSUS MERCURY FREE GOLD MINING METHODS}

J Bælum. Dept. of Occupational and Environmental Medicine, Odense University Hospital, DK-5000 Odense C, Denmark

\subsection{6/oemed-2018-ICOHabstracts.689}

Extracting gold from the ore among artisanal farmers have traditionally involved metallic mercury in order to amalgamate the gold and afterwards evaporate the mercury. Mercury poses well-known hazards to health and environment. Therefore alternative methods have been introduced to replace mercury. An alternative method is using borax, which is mixed with a concentrate of the heavy metals collected by washing the ore, and heated with a burner thereby extracting the gold.

Substituting a method by another always leads to concern about introducing unwanted health risks to the miners, their families, and the environment.

Mercury on one hand is a neurotoxin and the concentrations reached during amalgamation and evaporation are within the levels causing health effects to the worker and to bystanders. Additionally, the exposure to the family may be considerable due to evaporation from spills and from the debris after mixing mercury with the ore.

On the other hand heating borax emits boron to the air and the worker may be exposed. In animals boron in high doses can cause testicular impairment and impairment of fetal and infant neurodevelopment must be considered. This and possible other hazards related to the method may be taken into account.

The presentation will discuss these pro and cons when introducing an alternative method to extract gold not using mercury.

\section{$1637 \mathrm{~b}$ HEALTH EFFECTS OF MERCURY POISONING AMONG MINERS AND FAMILIES IN ASGM}

S Bose-O'Reilly. Institute and Outpatient Clinic for Occupational, Social and Environmental Medicine, WHO Collaborating Centre for Occupational Health, University Hospital Munich, LMU Munich, Germany

\subsection{6/oemed-2018-ICOHabstracts.690}

Introduction Mercury is used to extract the gold from the ore in artisanal small-scale gold mining areas (ASGM). The toxic mercury is a serious health hazard for miners and the general population. It is estimated that up to 100 million people are exposed.

Methods An extensive review of available data sources will be performed and combined with results of our own health assessments in ASGM.

Results Miners show tremor, ataxia and other neurological symptoms together with a raised body burden of mercury. Many of them were diagnosed with chronic inorganic mercury vapour intoxication. Children and the general population in mining areas show similar symptoms and have increased mercury levels. 14-19 million miners work globally, between 25\% and $33 \%$ of those miners are intoxicated.

Conclusions ASGM is causing severe negative health effects for miners and their families including children. Political action is needed to address those issues and to reduce the exposure with mercury in ASGM. Possible interventions are mercury free gold mining methods which are available. The health care sector needs to be strengthened to be able to diagnose and treat mercury intoxications. Further research is needed to analyse the specific health hazards of pregnant women, and infants.

\section{7c OCCUPATIONAL AND ENVIRONMENTAL BORON EXPOSURE AND HEALTH EFFECTS}

F Harari, M Vahter. Institute of Environmental Medicine, Karolinska Institutet, Stockholm, Sweden

\subsection{6/oemed-2018-ICOHabstracts.691}

Boron is a naturally occurring metalloid, widely distributed in nature. Boron is not essential for humans. People are exposed to boron mainly via drinking water, including bottled water, and food, but also occupationally. Little is known about potential health effects of boron exposure. In experimental animal studies, boron exposure has been shown to cause testicular lesions and affect early-life development, including bone malformations and lower birth weight. Studies on workers with occupational exposure to boron have, however, not revealed evidence for impaired fertility. On the other hand, our recent studies in the Andean part of northern Argentina, with elevated boron concentration in the drinking water in some villages, showed that serum boron concentrations above $80 \mu \mathrm{g} / \mathrm{L}$ during pregnancy were inversely associated with length and weight at birth. A follow-up study in the same study area showed that also infant boron exposure could be detrimental for the infant growth and that boys seem to be more susceptible than girls. In this presentation, a critical review of the scientific evidence available concerning occupational and environmental boron exposure and health effects will be presented and discussed.

\section{THE MERCURY-FREE GRAVITY BORAX METHOD IN ARTISANAL SMALL-SCALE GOLD MINING}

JF Thomsen. Department of Occupational and Environmental Medicine, Bispebjerg University Hospital, Copenhagen, Denmark

10.1136/oemed-2018-ICOHabstracts.692

Artisanal small-scale gold mining (ASGM) is the largest single anthropogenic source of mercury emissions. Mercury is used 
in excessive amounts to extract gold from crushed ore in ASGM. Through pollution of the air, water and nutrients, the mercury causes adverse health effects in miners and their families. However, ASGM can be performed without the use of mercury. This has been practiced for many years in a region in the Philippines with the gravity-borax method (GBM). With this method, the gold-containing ore concentrate is produced using a launder and a washing pan. As the last step, borax salt is added and the mixture blow-torched. The exposure to borax dust or fumes is limited and is not suspected of posing a health risk to the miner or the environment. The result is cleaner gold and no mercury spill. In order to spread the use of the GBM method, two intervention projects have been conducted in the Philippines. In combination with a civil society strategy, miners from the region using GMB have educated miners from other areas in the use of the GBM method. The success rate varied from area to area. In areas with a miners' organisation and back-up from the civil society, the miners were encouraged to shift method and the change was sustained. The intervention program is now introduced in Uganda and Mozambique with the help from miners using the GBM method. In Uganda, the activities are focused on the spread of information about the mercury-free method locally and regionally. In Mozambique, the core of the project is to determine the extent of ASGM and to introduce the GBM method.

\section{7e WHEN MINING SURROUNDS THE COMMUNITY: WORK, WELL-BEING, AND ENVIRONMENTAL MONITORING IN SMALL SCALE MINING IN THE PHILIPPINES}

JL Lu. National Institutes of Health, University of the Philippines Manila (UPM), Manila Philippines

\subsection{6/oemed-2018-ICOHabstracts.693}

This research on small scale gold mining (SSGM) in Benguet, Philippines draws from three different but complementary data sources in order to analyse work, well-being and environmental pollution in SSGM. The data sources were- 1. workplace inspection to assess working conditions, hazards, and work practices of miners coupled with interviews and focusgroup discussions; 2 . health assessment and laboratory examinations among indigenous miners; and 3. environmental monitoring of mercury in water samples across all 13 municipalities of Benguet. The work analysis showed accident risks from use of explosives, poor visibility in tunnels, exposure to dust during tunnelling, and chemical exposures to mercury and cyanide without protective equipment and proper ventilation. The workplace inspection of the underground tunnels showed safety infarctions including unsteady trenches, insufficient slopes, possibility of collapse of trenches, and the risk of subsidence. The sub-sample population of 89 SSGM reported prevalent health problems- hypertension (62\%), hypertensive cardiovascular disease (14\%), and dermatitis (4\%) Health injuries were secondary to blasting and stone crushing. Another data from a sub-population of 34 miners showed major causes for hospitalisation were trauma, ulcers, kidney and cardiac diseases. Low back pain was common and associated with heavy lifting $(p=0.001)$. Reticulocyte count was associated with total lifetime mining hours $(p=0.033)$. The mental status examination showed most deficits in repeat phrase and recent memory. For the environmental monitoring of mercury in 90 surface water and 40 drinking water samples, a considerable percentage exceeded the maximum contaminant level (MCL) of both the Philippine guideline $(0.001 \mathrm{mg} / \mathrm{L}$ for drinking sources, $0.002 \mathrm{mg} / \mathrm{L}$ for surface waters), and EPA $(0.002 \mathrm{mg} / \mathrm{L})$, above which levels can cause risk to health. All the three different but complementary data sources show the need for an occupational and environmental agenda addressing the health-safety aspects and technical-social issues in mining.

\section{$1637 f$ LEGISLATION AND BEST PRACTICES IN SMALL-SCALE MINING IN THE PHILIPPINES}

SF Lu. College of Arts and Sciences, University of the Philippines Manila, Philippines

\subsection{6/oemed-2018-ICOHabstracts.694}

This study analyses the small-scale mining activities and the best practices for mercury-free gold mining. The data were based on literature, national laws and modules for small-scale mining, as well as interviews of major stakeholders in small scale mining in the Philippines. Currently, there are two national legislations on small-scale mining and an executive order to compliment these national laws, Presidential Decree 1899, which allowed for small-scale mining in the Philippines, and Republic Act 7076, which introduced guidelines for local miners on artisanal mining. Executive Order 79 prohibits the use of mercury in small-scale mining, however it goes against other legislative acts in place regulating the use of mercury for industrialization. Furthermore, the Order states that smallscale mining is not allowed outside the 'Minahang Bayan (People'sMining)', which was established to regulate small-scale mining. This is inconsistent with President Decree 1899 which allows for mining activities. There are thousands of illegal small-scale mining, as they cannot adhere to the administrative requirements set by the local government units. Hence, there is a need to revise and amend the existing laws to serve and benefit the local Filipino miners. Among the best practices in the approach to mercury-free mining in the Philippines showed the need for a participatory approach among major stakeholders such as the small scale miners, local government, and civil society-advocacy groups, the need for technical knowledge of shifting to mercury-free mining, respect for culture of the indigenous miners, and capacitating strategies to maintain the mercury-free technology in mining. There are also corollary programs aimed to promote mining revenue, compliance among miners for increased awareness, and to decrease hazards and conflicts. Hence, there is a need for the following- a ground-to-top reformulation of the law to cater to the needs of the miners and a harmonisation of national laws with international guidelines.

\section{MINING OCCUPATIONAL SAFETY AND HEALTH: HAZARDS AND GOOD PRACTICES IN FORMAL AND INFORMAL MINING}

${ }^{1}$ Erik Jørs*, ${ }^{2}$ Jane Froelund Thomsen. 'Department of Occupational and Environmental Medicine, Odense University Hospital, Odense, Denmark; ${ }^{2}$ Department of Occupational and Environmental Medicine, Bispebjerg University Hospital, Copenhagen, Denmark

10.1136/oemed-2018-ICOHabstracts.695 